\title{
THE EFFECT OF CYTOKININS ON FLAX SEED GERMINATION AT LOW TEMPERATURE
}

\author{
SYLWIA BUKŁAHA, IRENA NIEDŹWIEDŹ-SIEGIEŃ \\ University of Białystok, Institute of Biology \\ Świerkowa 20B, 15-950 Białystok, Poland \\ e-mail: siegien@uwb.edu.pl
}

(Received: January 23, 2006. Accepted: March 18, 2006)

\begin{abstract}
Germination of flax seeds (Linum usitatissimum L., cv. Szafir) at $5^{\circ} \mathrm{C}$ was enhanced by continuous white light, gibberellin $\mathrm{A}_{3}\left(\mathrm{GA}_{3}\right)$, kinetin and benzylaminopurine. $\mathrm{GA}_{3}$ and kinetin at physiological concentrations $\left(10^{-8}-10^{-6}\right.$ M) improved significantly germination in darkness. Stimulatory effect of benzylaminopurine was visible only in the light. Almost no effect of zeatin and isopentenyladenine (2iP) on germination was observed. Possible causes of this differences were suggested.
\end{abstract}

KEY WORDS: cytokinins, germination, gibberellin, Linum usitatissimum L., seeds, low temperature.

\section{INTRODUCTION}

The effects of the phytohormones, especially gibberellins and cytokinins, in stimulation of seed germination at unfavourable conditions have been frequently observed (El-Keblawy et al. 2005; Thomas 1992; Gulzar and Khan 2002). Germination of some seeds under water stress can be improved by treatment with these growth regulators (Heikal et al. 1982; Niedźwiedź-Siegień and Lewak 1992). Similarly, the phytohormones modify the temperature requirements of germination of some seeds (Wang et al. 1996; Thomas and Davies 2002). Moreover, gibberellins and cytokinins can be involved in the light-regulated germination of some seeds (Thomas et al. 1997; Zagórski and Lewak 1983).

The germination-stimulatory effect of light was attributed to light-mediated stimulation of GA synthesis and/or the sensitivity to this hormones (Hilhorst and Karssen 1992; Yamaguchi and Kamiya 2002). The observations, that cytokinins are effective only in the light or in darkness in presence of gibberellins (Thomas 1992) and that the effectiveness of different cytokinins is not the same in different seeds (Poggi-Pellegrin and Bulard 1978) indicate that the interaction between light and cytokinins is more complex.

In many crop plants, seed germination and early seedling growth are the most sensitive stages to environmental stresses (Foolad et al. 2003). Although flax (Linum usitatissimum L.) is considered to be a cool season crop, air temperature below $10^{\circ} \mathrm{C}$ in the spring may inhibit its growth and development, which can delay flowering $(\mathrm{Gu}-$ sta et al. 1997). The germination of wild flax species $L i$ num catharcticum $\mathrm{L}$. was temperature- and light-dependent (Van Tooren and Pons 1988). It was also shown (Heikal et al. 1982) that osmotically inhibited germination of Linum usitatissimum L. seeds can be improved by a treatment with gibberellin.

Therefore, it seemed of some interest to study the effects of different cytokinins on dark- and light-germination of flax seeds at low, unfavourable temperature. Gibberellin $A_{3}$ effects were used as a reference.

\section{MATERIALS AND METHODS}

Seeds of oil flax (Linum usitatissimum L., cv. Szafir) were obtained from Plant Breeding Station at Borowo (West Poland), and stored dry at $4^{\circ} \mathrm{C}$ in darkness for 6-12 months before experiments.

Seeds were placed in lots of 30 in $9 \mathrm{~cm}$ diameter Petri dishes lined with 2 discs of filter paper moistened with 8 $\mathrm{ml}$ of distilled water or an appropriate solution of a growth regulator: gibberellin $A_{3}\left(G_{3}\right)$, kinetin, benzylaminopurine (BA), isopentenyladenine (2iP) and zeatin (Sigma). Dishes were incubated in darkness (in black paper boxes) or under continuous white light (white fluorescent tubes "Philips", $90 \mu \mathrm{mol} \mathrm{m}^{-2} \mathrm{~s}^{-1}$ ) in temperature controlled chamber ("Fitotron", Sanyo, Japan), where the temperature was kept constant within $\pm 1^{\circ} \mathrm{C}$. Germination was studied at temperature range from 5 to $30^{\circ} \mathrm{C}$ at the seed level. For the study of the effects of hormones, seeds were incubated at $5^{\circ} \mathrm{C}$ only. 
Protrusion of radicle through the seed coat was taken as a criterion of germination. The germinated seeds were counted every day under a dim green safety light.

Each experiment was performed in 4 replicates and repeated at least twice. The results are presented as mean values \pm SD. The statistical differences were tested using one way analysis of variance (ANOVA), $\mathrm{P}<0.05$.

\section{RESULTS}

\section{AND DISCUSSION}

Optimal germination of flax seeds occurred at temperatures of $15-25^{\circ} \mathrm{C}$ (Fig. 1A). Under these conditions most seeds (above $80 \%$ ) germinate within four days, both in the light and in darkness (Fig. 1A). Low temperature, however, similar to other seeds (e.g. Gill 2003; Guillermo 2006), causes a slowing of germination of flax seeds. Additionally, at low temperature $\left(5-10^{\circ} \mathrm{C}\right)$ their germination was substantially enhanced by light (Figs 1A, B), indicating that the seeds become positively photoblastic. It has been already reported for the seeds of Calluna vulgaris (Thomas and Davies 2002), Trifolium repens (Niedźwiedź-Siegień and Lewak 1988), Amaranthus hypochondriacus (Aufhammer et al. 1998) and Artemisia species (Kazuo et al. 2006) that photosensitivity of germination changed with temperature.

Taking the above into account, the effects of hormonal treatments on flax seeds germination were checked at the lowest studied temperature $\left(5^{\circ} \mathrm{C}\right)$ only. Dark germination was improved by low concentrations of $\mathrm{GA}_{3}\left(10^{-8}-10^{-7} \mathrm{M}\right.$, Fig. 2). However, similarly to other seeds (Miyoshi and Mii 1995; Wang et al. 1996) higher levels of this hormone had an inhibitory effect, both on light and in darkness. It can be assumed, that low temperature, that slowed down the germination, increased simultaneously the sensitivity of flax seeds to $\mathrm{GA}_{3}$. The similar substitution by GA treatment the effect of light, indicating its influence on GA biosynthesis, and/or on the increased sensitivity to the hormo-
A

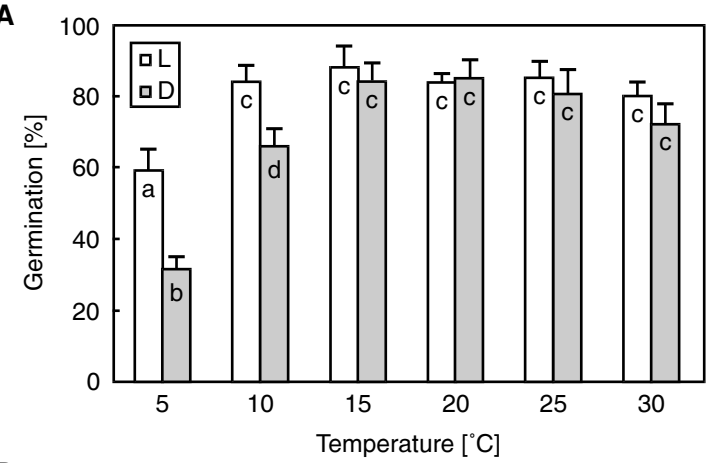

B

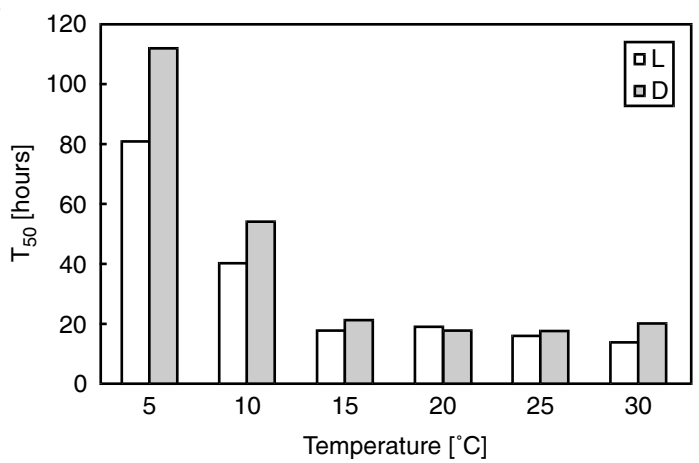

Fig. 1. A - effect of different temperatures on the final percent of germination of flax seeds after 4 days in darkness (D), or under continuous white light (L). Vertical bars indicate \pm SD. Means marked with the same letters are not significantly different $(\mathrm{P}<0.05)$ according to ANOVA analysis; B - effect of continuous white light on flax seed germination at different temperatures. Times (h) necessary for $50 \%$ germination on the light (L) and in darkness (D) were calculated from extrapolated germination curves. SD did not exceed $10 \%$ for germination tests (examples in figures $1 \mathrm{~A}, 2$ and 3 ).

ne (Casal and Sanchez 1998; Yamaguchi and Kamiya 2002) was observed earlier (Derkx et al. 1994).

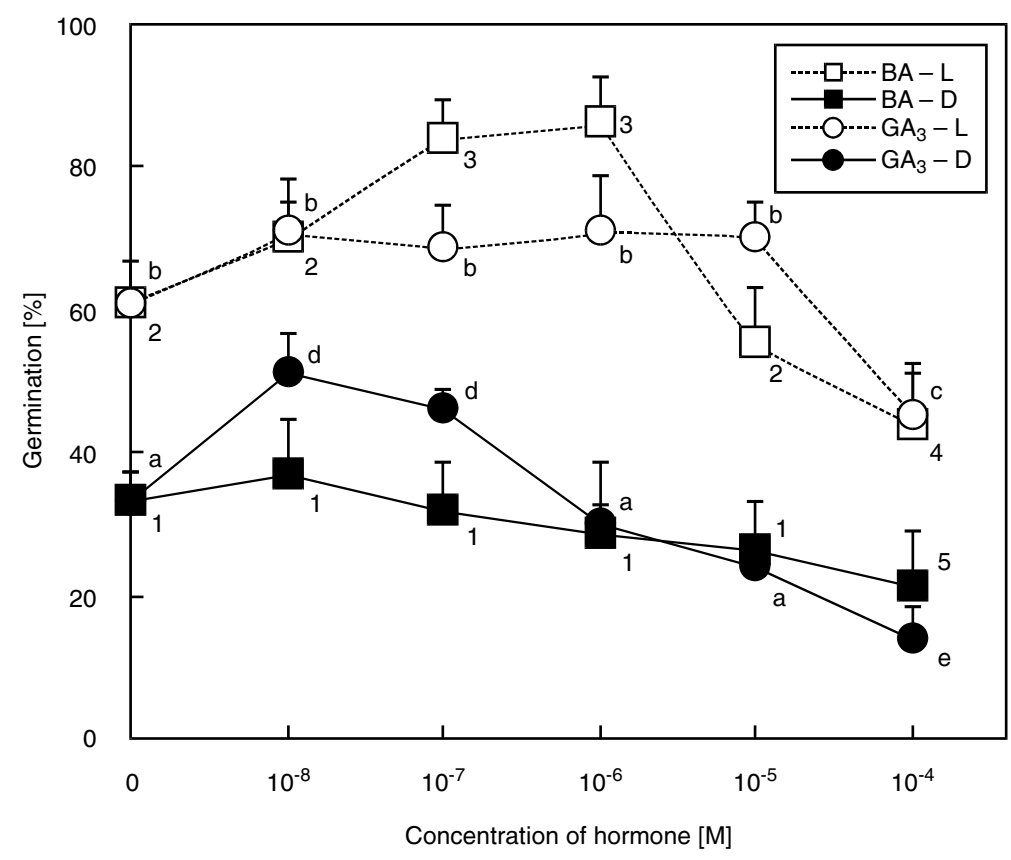

Fig. 2. Effect of $\mathrm{GA}_{3}$ and benzylaminopurine (BA) on germination of flax seeds for 4 days at $5^{\circ} \mathrm{C}$ in darkness (D) and after continuous illumination with white light (L). Vertical bars indicate \pm SD. Means marked with the same letters (for $\mathrm{GA}_{3}$ ), or numbers (for BA) are not significantly different $(\mathrm{P}<0.05)$ according to ANOVA analysis. 


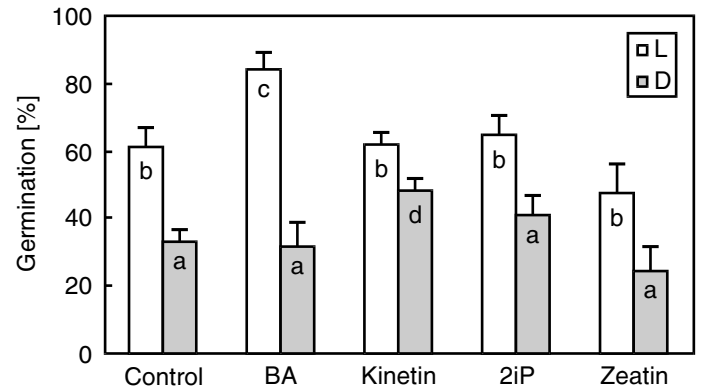

Fig. 3. Effect of different cytokinins $\left(10^{-7} \mathrm{M}\right)$ on flax seeds germination for 4 days at $5^{\circ} \mathrm{C}$ in darkness (D) and after continuous illumination with white light (L). Vertical bars indicate \pm SD. Means marked with the same letters are not significantly different $(\mathrm{P}<0.05)$ according to ANOVA analysis.

Germination of flax seeds was enhanced significantly (by $40 \%$ of control) by BA $\left(10^{-7}-10^{-6} \mathrm{M}\right)$, but only on light (Fig. 3). This observation could indicate, that for stimulatory effect of BA a certain level of $\mathrm{P}_{\mathrm{fr}}$ is necessary as it has been suggested for other seeds (Thomas 1992; Thomas et al. 1997). According to some hypotheses, cytokinins could be the "mediators" of light, and may be aiding in overcoming the embryonic block in germination (Thomas et al. 1997; Brault and Maldiney 1999). However, for better understanding the interaction of light and cytokinin in the regulation of flax seed germination at low temperature the results of experiments with monochromatic light would be helpful.

Other cytokinins (kinetin, 2iP, zeatin) were applied at the same concentrations range $\left(10^{-8}-10^{-4} \mathrm{M}\right)$ as it was shown for BA in figure 2 (results not shown). To display the different cytokinins influence on germination of flax seeds, the effects of one $\left(10^{-7} \mathrm{M}\right)$ the most effective concentration of these phytohormones were shown (Fig. 3). Kinetin stimulated the germination of the flax seeds in darkness only, but the degree of stimulation (by $50 \%$ ) was similar to that of BA in light. On the other hand there was almost no effect of isoprenoid cytokinins (zeatin and 2iP) on flax seeds germination. Similarly, stimulatory effects of BA and kinetin and no effects of $2 \mathrm{iP}$ and zeatin on lettuce seed germination was earlier observed (Poggi-Pellegrin and Bulard 1976).

The significant effect of aromatic cytokinins (BA and kinetin) on germination and almost no effects of the aliphatic ones (zeatin and 2iP, Fig. 3) can result from the rapid destruction of the last ones by native plant enzymes (PoggiPellegrin and Bulard 1976). Another explanation of these results may be, that the rate of penetration of different cytokinins into the seeds is different (Thomas 1992). Kinetin and BA would reach the embryonic tissues faster than aliphatic cytokinins, thus their effect would be higher. It is not excluded that both these mechanisms are operating simultaneously.

The stimulatory effect of $\mathrm{GA}_{3}$, BA and kinetin on germination of flax seeds at low temperature have been also observed for corn (Zea mays) and soybean (Glycine max) seeds germinated under the same stress (Wang et al. 1996). These hormones are also involved in alleviation of salinity effects during seed germination of Prosopis juliflora (ElKeblawy 2005), Suaeda salsa (Li et al. 2005), and also wa- ter stress during germination of Cicer arietinum, seeds (Kaur et al. 1998). There are some data, that all these stresses do affect water status of the cell and delay seed germination by causing water stress (Liptay and Schopfer 1983). Moreover, there is a suggestion that same genes might control the rate of seed germination under cold, salt and drought stress (Foolad et al. 2003). All stress conditions usually cause the imbalance of growth regulators, resulting in increased levels of inhibitors, and a decrease in endogenous growth promoters (Bewley and Black 1994; Hare et al. 1997). So, the increase in flax seed germination under temperature stress, after exogenous application of $\mathrm{GA}_{3}$, kinetin or BA may be attributed to the ability of these growth regulators to reduce the moisture requirement or to enhance water uptake during germination (El-Keblawy et al. 2005). It cannot also be excluded, that these regulators may enhance the activities of some enzymes involved in sugars' metabolism during germination of flax seeds, as it was suggested for germination of other seeds under water stress conditions (Kaur et al. 1998, 2000).

\section{ACKNOWLEDGEMENTS}

The authors are grateful to Prof. Stanisław Lewak for fruitful discussions and reading of the manuscript.

\section{LITERATURE CITED}

AUFHAMMER W., CZUCZUROWA D., KAUL M., KRUSE H.-P. 1998. Germination of grain amaranth (Amaranthus hypochondriacus $\times$ A. hybridus): effects of seed quality, temperature, light, and pesticides. Eur. J. Agronomy 8: 127-135.

BEWLEY J.D., BLACK M. 1994. Seeds: Physiology of Development and Germination. Plenum Press. London.

BRAULT M., MALDINEY R. 1999. Mechanisms of cytokinin action. Plant Physiol. Biochem. 37: 403-412.

CASAL J.J., SANCHEZ R.A. 1998. Phytochrome and seed germination. Seed Sci. Res. 8: 317-329.

DERKX M.P.M., VERMEER E., KARSSEN C.M. 1994. Gibberellins in seeds of Arabidopsis thaliana: biological activities, identification and effects of light and chilling on endogenous levels. Plant Growth Regul. 15: 223-234.

El-KEBLAWY A., Al-RAWAI A. 2005. Effects of salinity, temperature and light on germination of invasive Prosopis juliflora (SW.) D.C. J. Arid Environ. 61: 555-565.

FOOLAD M.R., SUBBIAH P., KRAMER C., HARGRAVE G., LIN G.Y. 2003. Genetic relationship among cold, salt and drought tolerance during seed germination in an interspecific cross of tomato. Euphytica 130: 199-206.

GILL P.K., SHARMA A.D., SINGH P., BHULLAR S.S. 2003. Changes in germination, growth and soluble sugar content of Sorghum bicolor (L.) Moench seeds under various abiotic stresses. Plant Growth Regul. 40: 157-162.

GUSTA L.V., O'CONNOR B.J., BHATTY R.S. 1997. Flax (Linum usitatissimum $\mathrm{L}$.) responses to chilling and heat stress on flowering and seed yield. Can. J. Plant Sci. 77: 97-99.

GUILLERMO F., PAULA V. 2006. Dormancy and germination in three Acacia (Fabaceae) species from central Argentina. Seed Sci. Res. 16: 77-82.

HARE P.D., CRESS W.A., van STADEN J. 1997. The involvement of cytokinins in plant responses to environmental stress. Plant Growth Regul. 23: 79-103.

HEIKAL M.M., SHADDAD M.A, AHMED A.M. 1982. Effect of water stress and gibberellic acid on germination of flax, sesame and onion seeds. Biol. Plant. 24: 124-129. 
HILHORST H.W.M., KARSSEN C.M. 1992. Seed dormancy and germination: the role of abscisid acid and gibberellins and the importance of hormone mutants. Plant Growth Regul. 11: 225$-238$.

KAUR S., GUPTA A.K., KAUR N. 1998. Gibberellic acid and kinetin partially reverse the effect of water stress on germination and seedling growth in chickpea. Plant Growth Regul. 25: 29-33.

KAUR S., GUPTA A.K., KAUR R. 2000. Effect of GA 3 , kinetin and indole acetic acid on carbohydrate metabolism in chickpea seedlings germinating under water stress. Plant Growth Regul. 30: 61-70.

KAZUO T., LIPING Z., KENJI O. 2006. Seed germination and seedling emergence of three Artemisia species (Asteraceae) inhabiting desert sand dunes in China. Seed Sci. Res. 16: 61-69.

LI W., LIU X., KHAN A., YAMAGUCHI S. 2005. The effect of plant growth regulators, nitric oxide, nitrate, nitrite and light on the germination of dimorphic seeds of Suaeda salsa under saline conditions. J. Plant. Res. 118: 207-214.

LIPTAY A., SCHOPFER P. 1983. Effect of water stress, seed coat restraint, and abscisic acid upon different germination capabilities of two tomato lines at low temperature. Plant Physiol. 73: 935-938.

MIYOSHI K., MII M. 1995. Phytohormone pre-treatment for the enhancement of seed germination and protocorm formation by the terrestrial orchid, Calanthe discolor (Orchidaceae), in asymbiotic culture. Scienta Hortic. 63: 263-267.

NIEDŹWIEDŹ-SIEGIEŃ I., LEWAK S. 1988. Phytochrome involvement in inhibition of germination of white clover seeds at low temperature. Acta Physiol. Plant. 10: 301-306.
NIEDŹWIEDŹ-SIEGIEŃ I., LEWAK S. 1992. Growth regulators differentially affect photosensitivity induced by low temperature and osmotic stresses in germinating white clover seeds. Plant Growth Regul. 11: 133-137.

POGGI-PELLEGRIN M.-C., BULARD C. 1976. Interactions between abscisic acid, gibberellins and cytokinins in grand rapids lettuce seeds germination. Physiol. Plant. 36: 40-462.

THOMAS T.H. 1992. Some reflections on the relationship between endogenous hormones and light-mediated seed dormancy. Plant Growth Regul. 11: 239-248.

THOMAS T.H., DAVIES I. 2002. Responses of dormant heather (Calluna vulgaris) seeds to light, temperature, chemical and advancement treatments. Plant Growth Regul. 37: 23-29.

THOMAS T.H., HARE P.D., VAN STADEN J. 1997. Phytochrome and cytokinin responses. Plant Growth Regul. 23: 105-122.

VAN TOOREN B.F., PONS T.L. 1988. Effects of temperature and light on the germination in chalk grassland species. Funct. Ecol. 2: 303-310.

WANG Q., ZHANG F., SMITH D.L. 1996. Application of $\mathrm{GA}_{3}$ and kinetin to improve corn and soybean seedling emergence at low temperature. Environm. Exp. Bot. 36: 377-383.

YAMAGUCHI S., KAMIYA Y. 2002. Gibberellins and light-stimulated seed germination. J. Plant Growth Regul. 20: 369$-376$.

ZAGÓRSKI S., LEWAK S. 1983. Interactions between hydrogen cyanide, gibberellin, abscisic acid and red light in germination of lettuce seeds. Physiol. Plant. 59: 95-98. 